\title{
6. The virtual newsroom: Using wiki technology for training student print journalists
}

\section{ABSTIRACI}

This article analyses how, during a one-year project, a wiki was established to enable student print journalists to collaborate to create a professional print news product. The idea was to replicate a professional newsroom where a second set of eyes is always cast on material before publication but to do so in an environment that provided flexibility of access and therefore accommodated demanding student timetables. The wiki provided a space for student peer editing of news and feature stories enhancing the collaborative, creative and critical literacies of those involved. The article explores how peer review (in the writing process) helped these reviewers become better writers and ultimately better journalists. It reviews literature regarding the use of wikis as a collaborative learning tool and uses student surveys to assess the success of the pilot project.

\section{SUSAN HETHERINGTON}

Queensland University of Technology

\section{Introduction}

7 ENOWNED Chicago Daily Herald newspaper columnist Jack Mabley (2004) described a print newsroom as a 'raucous' place 'where the noise level resembled the Chicago Board of Trade trading pits'. Online columnist Rip Rense (2003) goes further, noting:

Newspapers are loud, rip-roaring, raucous, chaotic, tumultuous, nutso collisions of humanity and idea! They are places where information runs head-on into heart and mind, and gets all twisted up in ink and paper and headlines and deadlines. They're frenzied, messy rooms where you tear your hair out, or just lose it naturally. They're homes to ulcer and tantrum, wit and prank, romance and divorce, good conversation and 
bad office politics. They're salons, where sports guys talk to news guys (or gals), where editors yack with copyboys (or gals), where story ideas come from wisecracks about the morning headlines.

What print newsrooms are quiet places where journalists work in isolation? Journalism is not a solo profession. Journalism is about collaboration. Indeed in Online Journalism Review, Mark Glaser (2004) notes 'journalism relies on collaboration to build trust'.

However, much journalism education - particularly in the early years involves students creating copy alone - and submitting it to tutor for evaluation. Teaching and learning happens in an environment that more closely mimics a classroom than a newsroom. This shortfall in the nature of journalism education has been the subject of much debate with both the industry and journalism educators calling for a reconsideration in how the craft is taught at university level (Carey, 2000, p. 14; Quinn 1999, p. 158). It is not a problem unique to journalism as Winter and Maisch (1996) note that the gulf between skills taught in university and those in demand by industry is a persistent source of tension. The call to more closely align journalism education with the demands of the industry has been highlighted also by educational theorist John Biggs (1999, p. 41), who notes that there are dilemmas between what universities traditionally do and what the industry demands in areas beyond journalism. He notes 'would-be professionals are trained in universities to label, differentiate, elaborate and justify, when what they need out in the field is to execute, apply and prioritise'. This project sought to find a way to shift the balance.

\section{The project}

In 2005, funding was received under the Teaching and Learning Development Large Grants Scheme to investigate and implement innovative collaborative learning initiatives in Queensland University of Technology's Humanities and Human Services and Creative Industries faculties. Eleven especially targeted units were selected to be included in the project. The grant application stated that the project was 'based on the recognition that evolving work practices and the proliferation of Information and 
Communication Technologies (ICTs) mean that generic capabilities for students increasingly include critical, collaborative and creative ICT literacies. Accordingly, it is essential that academic staff share these literacies and are empowered to evaluate, manipulate and integrate a range of technologies into innovative pedagogical practices. The project seeks to create integrated learning environments that enable students to develop critical, collaborative and creative ICT literacies for real world contexts' (2005).

The project recognises the growing trend to use online technology to increase the learning possibilities for students and to increase student engagement. Seagrave, Holt and Farmer (2005) comment on 'the move to online education is accompanied by a raft of online teaching and learning policies carrying an imperative of engaging more broadly and deeply with the technologies'.

It also took on board the theory of Professsor Graham Gibbs (1992) considered a pioneer of higher education development - who says that when considering changes to course design teachers need to remember:

- the motivational context

- that students need to be active not passive

- Students need to interact with others including peer tutoring

- Students need to bring with them a well-structured knowledge base

The selected Journalism unit was a final year praxis unit, News Production, designed to sharpen students' print, broadcast or online journalistic capabilities just before graduation and to assist them to adapt to a newsroom environment. The aim of the unit is to help new graduates better understand media environments and prepare them to work in news media, ethically, thoughtfully, interactively and efficiently.

The News Production journalism project had both print and television news components. The project aimed to create virtual newsrooms designed to replicate the learning that takes place in a professional newsroom where journalists collaborate to produce and present news for various mediums. In the QUT journalism environment, staff needed to establish processes and techniques that allowed for the integration of a strong learning and teaching component into a production process that was aimed to produce professional and commercial standard product. This article centres on the print praxis component of the project where the aim was to balance two competing needs - the publication of a professional print product that attracts commercial 
sponsorship and for this imperative to co-exist with the need to use student work and for students to critique the work of their peers. Students electing to concentrate on print for their final praxis were involved in creating a new glossy news and lifestyle magazine called kuRB. The magazine was launched by QUT Journalism in 1995 as a free publication distributed through letterboxes in the Kelvin Grove Urban Village (where QUT's Journalism Discipline is located) and to houses and businesses in the surrounding one kilometre radius. The developers of the Village Centre provided funding of $\$ 10,000$ to launch the new product. The Queensland State Government, through the Department of Housing, came on board as a second major sponsor in the second edition in November 2005. The substantial level of corporate and government support demanded an appropriate level of professionalism in the final product. It was important, however, to never lose sight of the need to keep student learning and development at the core of what the initiative was about. Introducing a wiki as a collaborate learning and editing tool was seen as a perfect means of achieving this balance.

It worked on the concept that journalism staff believed through experience that students could more easily identify mistakes in the work of others than they could in their own. It built on this understanding to create a system where peer feedback played a greater part in the learning and teaching process. As new media consultant Nick Carbone commented, 'Peer review - students commenting on students writing - is one of the most beneficial things you can do in any course where there's writing'. Thomasson (1996) argues, in fact, that newsrooms need more collaboration. He says 'the dearth of collaborative editors in our business is evidence of a massive blind spot in newsroom management: the failure to examine and think critically about the relation between editors and writers. We need more collaboration.'

Brooks and Sissors (2001) also note an increasing — and beneficial — trend to increased collaboration in newsrooms: 'Proponents of the team system insist that it improves story content because more people are involved in the story from the outset.'

The collaborative space where peer review took place in this project was a specially created wiki. The use of the wiki allowed students working on kuRB to incorporate a student review component in the writing process - an activity previously impossible until students had mastered specialist newspaper technologies. Further it recognised that simply employing the technology of 
the newsroom to the student environment was not an option. As van der Vliet and Deacon (2004) note, 'it is impractical simply to use the technology of professionals as this would typically be too expensive to develop and too time consuming to run'. Instead, like the model used by van der Vliet and Deacon who used computers 'to simulate a media workplace environment to focus on generic skills', this project employed a wiki to teach industry standard skills without industry-standard technology.

This new wiki editing stage happened before material passed on to subeditors and required students to rewrite their work incorporating feedback before final sign-off was granted. As Sheridan Burns (2002) notes: 'writers who edit their own copy before giving it over to copy editors increase the likelihood of their work being published unchanged'. This project built on the professional newsroom culture where story review after peer feedback is established practice. Industry practice dictates that a second set of eyes looks over all written material and it has long been acknowledged that involvement with the peer review helps these reviewers become better writers. Also forcing students to apply their editing skills in a meaningful, practical context has a strong educational basis. As Professor Glenn (quoted in van der Vliet, 2002 ) comments, no matter how many times students are told 'your writing ought to be shorter, more functional, use active voice', it is only when these rules are put into practice in an authentic-seeming context that these skills are actually taught.

There is evidence that wikis are starting to be embraced in professional newsrooms. Jimmy Wales, founder of the Wikipedia, notes that the BBC is already using wikis to help streamline their work (quoted in Glaser, 2004). Glaser notes that 'wikis will be accepted into the newsrooms if they are for private collaboration among staffers'. It is precisely this model that this project adopted.

\section{The wiki}

According to wiki.org, a wiki is the simplest online database that could possibly work. 'Wiki is a piece of server software that allows users to freely create and edit web page content using any web browser,' the site notes (Leuf, 2002). The best known use of the wiki is the wikipedia which proclaims that the use of a wiki means 'anyone with access to an internet-connected computer can edit, correct, or improve information throughout the encyclopedia, simply by clicking the edit this page link' (2006). 
The beauty of the wiki is that it can be used with minimal training and requires no knowledge of web design or ability to use HTML. 'Even confirmed technophobes have grasped and mastered the system quickly,' says Brian Lamb (2004). The history function means that although anyone can change the wiki, earlier versions can be easily restored. In other words it is impossible for novices to 'break' anything that can't be fixed. Raitman et al also note that the wiki also engenders a sense of community. 'The nature of the wiki, in that it is fully editable, thus empowering the user with a sense of ownership and authority.' They note that these attributes create a relaxed environment in which students can collaborate. And Godwin-Jones (2003) comments 'Recent innovations - blogs, wikis and RSS feeds - may be less familiar but offer powerful opportunities for online collaboration'. He notes that the wiki is 'naturally suited for collaborative online projects'.

The wiki for this project was located on the university's servers at http://collaborate.ci.qut.edu.au/story/

Print students were divided into pairs. Each student posted on the wiki four stories to be considered for publication in kuRB. Their buddy was required to read and edit the stories after which a new, improved version of the story had to be submitted for publication a week later. Students were advised to be constructive in their feedback. As Kershner (2005) notes, 'good stories result from cooperation, not confrontation'.

While it could be argued that a very similar process of peer review could easily happen without wiki technology (it could be done with old-fashioned pen and paper) there were real advantages in using an online collaborative space such as a wiki. The first was convenience of access. Students could access and edit the work of their peers from any computer with internet access. The second was that wiki keeps a virtual paper trail. It is easy to determine what changes have been suggested and by whom. When a subeditor finally receives the copy to work with, he or she is easily able to see the process through which the final draft has arrived.

Students were required to edit work at both a micro and macro level. At the micro level, they were required to identify and correct errors in spelling and grammar and suggest improvements to expression. The history function makes it very easy to see what changes have been made at this level making it easier for them to learn from their mistakes.

The history function offered a line-by-line graphic display of how copy 
was changed. Even if the changes were numerous, the wikis functionality allowed them to be made without the changes raising problems for either editor or writer. As Wei et al (2005) comment: 'The simplicity of a wiki also makes it less burdensome to make small, spontaneous edits and may encourage team members to contribute more ideas or improve prose quality without the appearance of quibbling or nitpicking that might result if they were to recirculate a Word document with only a minor change.'

But the editing process was about more than just cosmetic changes. It was also about improving the content of the story by identifying areas where the story could have been improved by including new material or sources, updating, reordering or changing the priority of information. The discussion function of the wiki provided a platform where this macro level reviewing process could happen.

This offering from one student offering suggestions to her colleague about how to improve a story about a local café that allows patrons to dine with their dogs at their feet shows the level of thought students put into their suggestions:

I really like your story idea for this one.

I think the quotes from the customer-Stephanie - should be higher in the story, just so the idea of being against doggy dining is given as much emphasis as the ideas for it.

Also, maybe you need a few more quotes from other sources - perhaps another diner, or even a café [which] doesn't allow dogs. What are the council laws on doggy dining? Maybe you need a comment from a council representative.

I know that Pandemonium in Paddington doesn't allow dogs in their courtyard because the council won't permit it - against health regulations or something. So why is the Spring Hill cafe allowed them? Interesting angle maybe?

One last thing, you mention the name of the cafe and the suburb Spring Hill a bit, just be careful it doesn't read like an advertorial.

I hope my comments help.

Happy Regards

Students were surveyed at the end of the first semester trial of the project. Of the 24 students involved, 17 were located and surveyed and the result was overwhelmingly positive. Three propositions were put to the students. 
- It was useful having peer review of my stories

- Reviewing the stories of one of my peers will help me with my own writing

- The wiki was a useful device for peer review of work

They were then asked whether they strongly agreed, agreed, were neutral towards, disagreed or strongly disagreed with the statements. The results were overwhelmingly positive (see Graph 1).

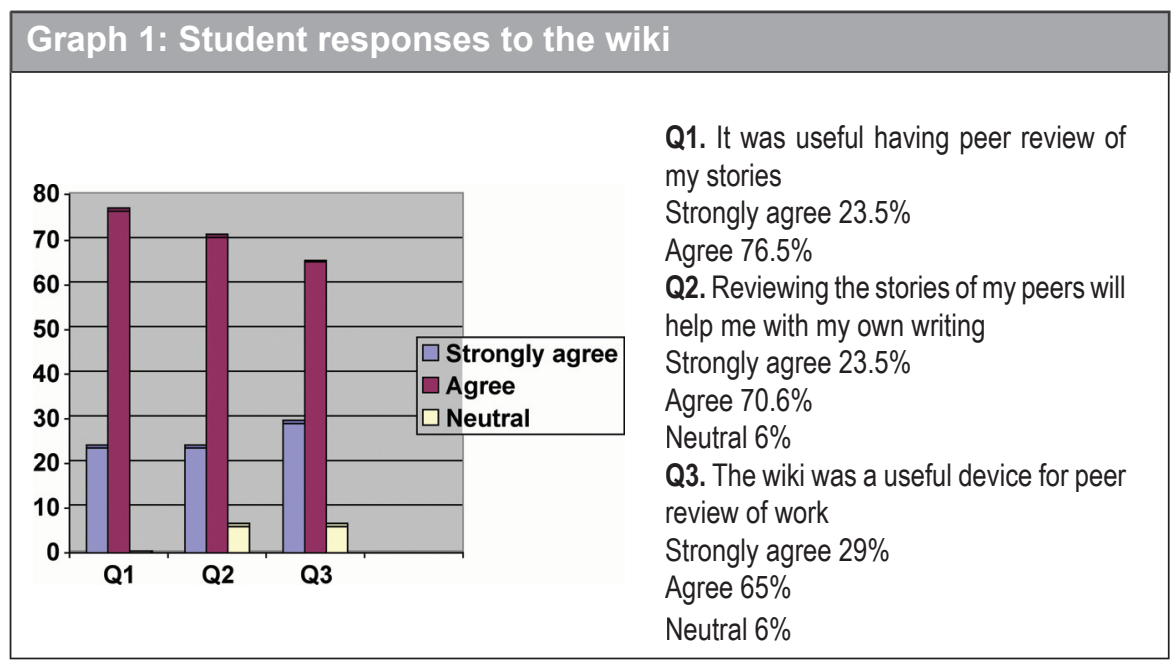

Students were also asked to nominate the best and the worst aspects about using the wiki.

The simplicity of the functionality of the wiki was well received by the students. 'Not having to compare hard copies of stories; it was easy to see what was changed,' one student said. 'Saved time having to do group work,' said a second while a third student noted that 'the edit function was a great tool'. Aspects of the collaborative process also received favourable comment from the students. When asked about the best aspect of using the wiki one student nominated 'Receiving feedback from peers and tutor'.

However, accepting peer feedback was not universally accepted. One student listed 'Knowing others were being critical of my work' when asked about the worst aspect of using the wiki. There were also issues about the functionality of the wiki which attracted student comment. Feedback included 
'Technology is scary' and 'Complicated — don't like computer systems' were among those submitted by the students.

There were also issues about the set-up that attracted student comment. In the first semester the wiki was used, students posted their stories on pages with headings such as James' first story. It was found that while this was a simple and straightforward naming convention, it made it difficult to track down a specific story.

One student noted: 'I think the organisation structure could be better, putting short slugs (and genre) on the stories, not just writers' names'. Recognising this shortfall, the second semester wiki version was set up using page names that included the student's name and a slug. This made tracking stories far easier.

\section{Conclusion}

'Wikis are already making their mark in higher education and being applied to just about every task imaginable,' says Lamb (2004), noting that their popularity is boosted by the fact that they are a low cost but effective communication and collaboration tool. This study reinforced this finding.

Students embraced the use of the new technology and the quality of the publication improved because of the improved copy being fed into the system. The first edition of kuRB took out the Journalism Education Association (JEA) 2005 Ossie Award for best occasional student publication, an honour not previously achieved by other publications put together by QUT students. Further, additional corporate sponsors, including the Brisbane City Council and the Institute of Creative Industries and Innovation, have since come on board in support of the publication.

As a result of the successful trial, work is now underway to imbed the use of the wiki into the production unit.

But there does need to be a word of caution. If educators intend to assess students on both their drafts and the quality of the feedback offered as part of the peer review process (which was the model applied here), a new level of assessment and therefore an increased workload will result. Stephen Segrave, one of the Deakin University academics behind the innovative computer-based journalism training resource Hotcopy, notes that e-learning tools and blended learning can be important training tools for aspiring journalists (2003). He notes: 'Journalism programmes in universities across Australia encounter 
large student numbers combined with relatively few staff and limited work placement opportunities for students'.

Collaborative online tools such as the wiki have an obvious part to play in educating would-be journalists in this environment. Care must be taken however, when designing tools to meet student demands, that more burdens are not placed on already stretched academic staff.

\section{References}

Towards critical, collaborative and creative ICT literacies: Integrating innovative on-campus and online learning environments. (2005). (Retrieved 28 August 2006): https://olt.qut.edu.au/udf/ICTLIT/admin/

Wikipedia: About. (2006). (Retrieved 28 August 2006): http://en.wikipedia.org/wiki/Wikipedia:About

Biggs, J. B. (1999). Teaching for quality learning at university. Buckingham: Society for Research into Higher Education \& Open University Press.

Brooks, B. \& J Scissors (2001). The art of editing. Needham Heights, Mass: Allyn \& Bacon.

Carbone, N. (n.d.). Strategies for teaching with online tools. (Retrieved 30 August 2006): www.bedfordstmartins.com/technotes/workshops/peerview.htm

Carey, J. W. (2000): Some personal notes on US journalism education, Journalism 1 (1): pp. $12-2$

Gibbs, G (1992). The nature and quality of learning. In Improving the quality of student learning (pp. 1-11). Bristol: Technical and Educational Services.

Glaser, M. (2004). Collaborative conundrum: Do wikis have a place in the newsroom. Online Journalism Review, October 9. (Retrieved 30 August 2006): http://ojr.org/glaser/1094678265.php

Godwin-Jones, R. (2003). Emerging techologies. Blogs and wikis: Environments for online collaboration. Language Learning \& Technology, 7(2): pp. 12-16.

Kershner, J. (2005). The elements of news writing. Boston: Pearson Allyn and Bacon.

Lamb, B. (2004). Wide open spaces. Wikis ready or not. Educause Review, September/October. 39(5): pp. 36-48.

Leuf, B and C Ward. (2002). wiki.org. (Retrieved 28 August 2006): http://wiki.org Mabley, J. (2004, October 12). Jack Mabley's Web Log.

Quinn, S. (1999). Teaching journalism in the information age, Australian Studies in Journalism 8: 1999: pp. 158-175.

Raitman, R; Augar, N; and Zhou, W. (2005). Employing wikis for online collaboration in the e-learning environment: case study. Paper presented at the Third International Conference on Information Technology and Applications, Sydney, July 4.

Rense, R. (2003, November 12). Quiet! This is a newsroom! The Rip Post.

Segrave, S. (2003). Hotcopy: simulations for learning professional journalism. Training and Development in Australia, 30 (3): pp. 6-10. 


\section{JOURNALISM DOWNUNDER}

Segrave, S; Holt, D; Farmer, J;. (2005). The power of the 6 three model for enhancing academic teachers' capacities for effective online teaching and learning: benefits, initiatives and future directions. Australasian Journal of Educational Technology, 21(1): pp. 118-135.

Sheridan Burns, L. (2002). Understanding journalism. London: Sage.

Thomasson, D. (1996, August 31). A plea for collaboration. Editor and Publisher, 129(35): pp. 48-50.

Van der Vliet E. (2002). Interviews with Professor Ian Glenn, Dr Jane Stadler, Rolf Behrens and various third-year film and media students. In MEG Research Report, University of Cape Town.

Van der Vliet, E. and A Deacon (2004). Media rich, resource poor: practical work in an impractical environment. British Journal of Educational Technology, 35 (2): pp. 213-222.

Wei, C; Maust, B; Barrick, J; Cuddihy, E; Spyridakis, J. (2005). Wikis for supporting distributed collaborative writing. Paper presented at the Society for Technical Communication 52nd annual conference, Seattle, May 8-11.

Winter, R.; and Maisch, M. (1996). Professional competence and higher education: The ASSET programme Falmer, London

Susan Hetherington is an associate lecturer in journalism in the Faculty of Creative Industries at the Queensland University of Technology. She worked in newspaper production in Australia and the United Kingdom and regularly appears on Australia's public broadcaster, the ABC. An earlier version of this article was presented at the Second Joint Journalism Education Association (JEA)/Journalism Education Association of New Zealand (JEANZ) conference at Auckland, New Zealand, 4-7 December 2006.

s.hetherington@qut.edu.au 